\title{
Assessment of the Depth of Clinically Detected Approximal Caries Lesions Using Digital Imaging Fiber-Optic Transillumination in Comparison to Periapical Radiographs
}

\author{
Auste Antipoviene' ${ }^{1}$, Monika Girijotaite ${ }^{2}$, Egle Aida Bendoraitiene ${ }^{3}$ \\ ${ }^{1}$ Department of Dental and Oral Pathology, Lithuanian University of Health Sciences, Kaunas, Lithuania. \\ ${ }^{2}$ Private practice. \\ ${ }^{3}$ Department of Preventive and Paediatric Dentistry, Lithuanian University of Health Sciences, Kaunas, Lithuania.
}

\author{
Corresponding Author: \\ Auste Antipoviene \\ Vaizganto 54, Kaunas \\ Lithuania \\ Phone: +37065060506 \\ E-mail: auste.antipoviene@gmail.com
}

\begin{abstract}
Objectives: The aim of present prospective clinical trial was to assess the depth of clinically detected approximal caries lesions using digital imaging fiber-optic transillumination in comparison to periapical radiographs.

Material and Methods: One calibrated examiner diagnosed 31 approximal carious lesions in 10 patients with a mean age of 21.8 (SD 1.1) years. The lesions were assessed using digital imaging fiber-optic transillumination (DIFOTI) and digital periapical radiographs (PA). Depending on the depth of the lesions, scores for demineralisation in PA (R) and DIFOTI (F) images were given by two examiners: R0/F0 - no demineralisation, R1/F1 - demineralisation confined to the outer half of the enamel, R2/F2 - into the inner half of the enamel, 3/3 - along the amelodentinal junction, R3/F3 - into the outer half of dentine, R4/F4 - into the inner part of the dentine. Spearman's rank correlation coefficient and kappa were calculated.

Results: Spearman's rank correlation coefficient between DIFOTI and PA was $0.031(\mathrm{P}>0.05)$, kappa was 0.077 . In $26 \%$ of the cases, DIFOTI showed higher scores of demineralisation, relative to PA. In $36 \%$ of the cases, PA showed higher scores of demineralisation than DIFOTI. PA showed demineralisation into the outer and inner half of the dentine in $89 \%$ of the cases with underlying shadow and in $70 \%$ of the cases with opacities.

Conclusions: Digital imaging fibre optic transillumination and periapical radiographs produce evaluations of the depth of approximal caries lesions that do not match.
\end{abstract}

Keywords: dental caries; dental digital radiography; diagnostic imaging; dental radiography; transillumination.

\section{Accepted for publication: 17 January 2020}

To cite this article:

Antipoviene A, Girijotaite M, Bendoraitiene EA.

Assessment of the Depth of Clinically Detected Approximal Caries Lesions Using Digital Imaging Fiber-Optic Transillumination in Comparison to Periapical Radiographs

J Oral Maxillofac Res 2020;11(1):e3

URL: http://www.ejomr.org/JOMR/archives/2020/1/e3/v11n1e3.pdf

doi: $10.5037 /$ jomr.2020.11103 


\section{INTRODUCTION}

In daily practice, visual examination is the primary mode of inspecting teeth. Caries lesions on occlusal and accessible smooth surfaces of teeth are easily detected by this basic method. However, approximal teeth surfaces are in contact with adjacent teeth, and it is therefore not possible to view them directly. Tooth separation enables practitioners to conduct a direct visual examination of such surfaces and the method has been proven effective in identifying cavitated carious lesions in approximal surfaces. That said, tooth separation cannot be used on a daily basis, given the discomfort it imposes on the patient, along with an additional required visit. Also, clear visibility is not always feasible [1]. This limits practitioners' ability to make an appropriate treatment determination for approximal caries lesions. If the lesion is at an early stage, remineralisation is appropriate, while a formed cavity can be most effectively addressed by an operative intervention $[2,3]$. Therefore, to achieve an accurate diagnosis and choose the right treatment, a more objective assessment of the depth of a carious lesion is essential [4].

Radiographic caries detection is often used as an adjunctive method to clinical examination. In clinical practise, this method is useful when the practitioner is uncertain of a presence of a carious lesion and for patients who have a high caries risk $[2,5]$. However, this method underestimates the actual depth of a carious lesion [6]. Another negative aspect of radiographic examination is that, if improper angulation is used, there may be overlaying of approximal areas [7]. Also, ionizing radiation remains a concern, despite reduced radiation dosage in digital dental radiography [ [] .

These flaws have encouraged researchers to aim for more accurate and safer alternative methods to evaluate approximal carious lesions $[9,10]$. Digital imaging fiber-optic transillumination (DIFOTI) is one such modern method.

The aim of this study was to evaluate the capacity of digital imaging fiber-optic transillumination to detect the depth of approximal caries lesions in permanent teeth, relative to dental radiographs.

\section{MATERIAL AND METHODS Patient selection}

The study was conducted at the Clinic of Dental and Oral Pathology, Lithuanian University of Health Sciences from June, 2017 to March, 2018.
The study protocol was approved by Kaunas Regional Biomedical Research Ethics Committee (BECOF-13). Participation was voluntary. All participants read and signed informed consent forms. A sample consisting of 4 males and 6 females, aged from 21 to 24 years, was selected for the study.

The inclusion criteria were:

1. Patients older than 18 years;

2. Presence of clinically detected approximal caries lesions (underlying dentine shadow);

3. Willingness to participate in the study.

Exclusion criteria were:

1. Fillings in approximal surfaces;

2. Severely rotated teeth.

\section{Clinical examination}

One examiner (M.G.) performed the clinical examination. Prior to the study, one of the co-authors (E.B.) worked to extensively calibrate the examiner. Interexaminer agreement was very good (kappa $=0.8)$. Ten approximal caries lesions, on which calibration was performed, were not included in the study.

All patients were clinically examined under the same conditions and in the same dental chair at Clinic of Dental and Oral Pathology, using standard explorer (Stoma; Tuttlingen, Germany) and a mirror. Prior to the examination, a polishing paste was applied to the teeth with a rotary polishing brush, and then dried. The interdental spaces were then cleaned with dental floss. The clinical diagnosis was undertaken pursuant to the criterion of an underlying dark dentine shadow (with or without enamel breakdown). All included teeth were examined by two methods (digital periapical radiographs [PA] and DIFOTI).

\section{Digital radiography}

Digital radiographs were taken using the intraoral X-ray system (CS 2200 ${ }^{\circledR}$ - Carestream Health, Inc.; Rochester, New York, USA), paralleling technique, with settings of $70 \mathrm{kV}, 7 \mathrm{~mA}$ and a focus-to-skin distance of $20 \mathrm{~cm}$. The exposure time was adjusted to the region and individual patient. Digital radiographs were operated by an experienced technician (A.V.). The example of digital radiograph is shown in Figure 1.

\section{Digital imaging fibre optic transillumination}

The DIFOTI system (DIAGNOcam ${ }^{\mathrm{TM}}$ - KaVo Dental Gmbh; Biberach, Germany) was deployed in accordance with the manufacturer's instructions: the dental light was turned off, after which the hand piece 


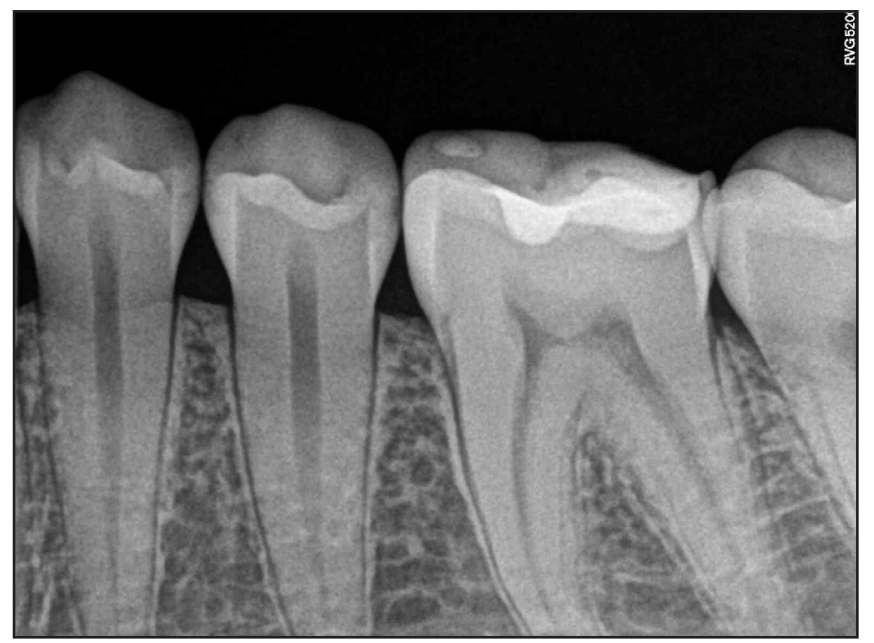

Figure 1. The example of digital radiograph (R2).

of the device was placed over each tooth with the previously detected approximal caries lesions. M.G. performed the DIFOTI examinations.

Each of the investigators (A.A. and M.G.) scored DIFOTI and PA images twice under the standardized conditions. DIFOTI and PA scores are shown in Tables 1 and 2. In cases where disagreements arose, the investigators discussed each disparity until a consensus was reached. The example of digital imaging fibre optic transillumination is shown in Figure 2.

\section{Statistical analysis}

To achieve an adequate power of $80 \%$, the minimal sample size was determined to be 25 approximal caries lesions. SPSS version 16.0 (SPSS, Inc., Chicago, Illinois, USA) was used for the analyses. Spearman's rank order correlation coefficient was calculated to enable evaluation of the correlation. Kappa values were calculated to investigate the agreement between the scores recorded by the two methods. Interpretation of kappa coefficient was as follows:

Table 1. Radiographic scores used to classify depth of approximal carious lesions

\begin{tabular}{c|l}
\hline Score & \multicolumn{1}{|c}{ Criterion } \\
\hline $\mathbf{R 0}$ & No demineralisation \\
\hline $\mathbf{R} 1$ & Demineralisation confined to the outer half of the enamel \\
\hline $\mathbf{R 2}$ & Demineralisation in the inner half of the enamel \\
\hline $\mathbf{3}$ & $\begin{array}{l}\text { Demineralisation broken enamel-dentine junction but } \\
\text { without obvious spread in the dentine }\end{array}$ \\
\hline $\mathbf{R 3}$ & $\begin{array}{l}\text { Demineralisation with obvious spread in the outer half of } \\
\text { the dentine }\end{array}$ \\
\hline $\mathbf{R 4}$ & $\begin{array}{l}\text { Demineralisation with obvious spread in the inner half of } \\
\text { the dentine }\end{array}$ \\
\hline
\end{tabular}

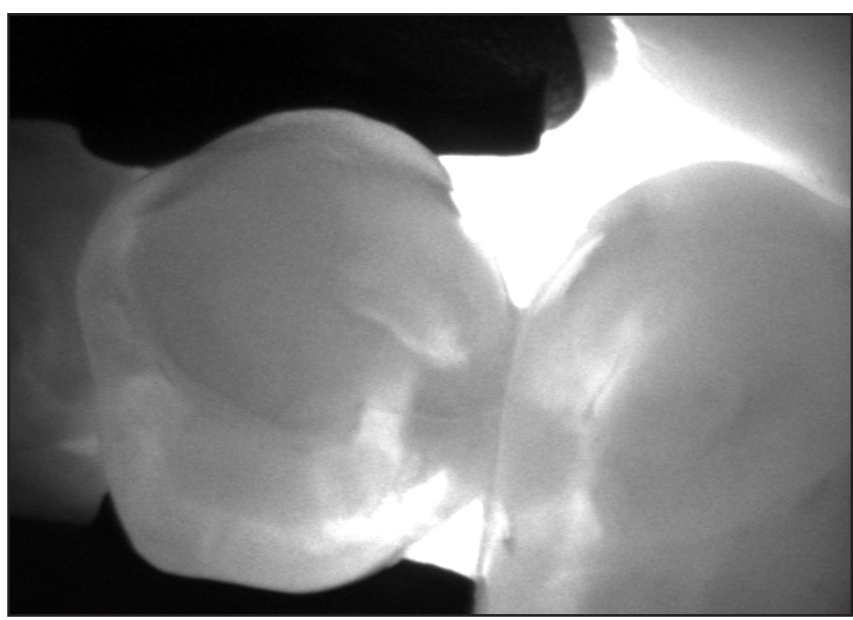

Figure 2. The example of digital imaging fibre optic transillumination $(\mathrm{F} 3)$.

- 0.81 to 1 - very good agreement;

- 0.61 to 0.8 - good agreement;

- 0.41 to 0.6 - moderate agreement;

- 0.21 to 0.4 - fair agreement;

- $\quad<0.2$ - poor agreement.

Statistical significance level was defined at $\mathrm{P}<0.05$.

\section{RESULTS}

Altogether, 31 approximal caries lesions were included in this study, 9 of which were in molars and 22 of which were in premolars.

Of the 31 lesions, most of the radiographically detected caries lesions were spread within dentine and none of those included in the study sites were identified in the outer half of enamel (Figures 3 and 4). Table 3 presents the cross-tabulation for DIFOTI (F) diagnostic scores, relative to the radiographic $(\mathrm{R})$ diagnostic scores.

A comparison of the DIFOTI and PA scores of demineralization depth revealed that the methods yielded different results. To evaluate the correlation

Table 2. Digital imaging fiber-optic transillumination scores used to classify depth of approximal carious lesions

\begin{tabular}{c|l}
\hline Score & \multicolumn{1}{|c}{ Criterion } \\
\hline F0 & No demineralisation \\
\hline F1 & Demineralisation confined to the outer half of the enamel \\
\hline F2 & Demineralisation in the inner half of the enamel \\
\hline $\mathbf{3}$ & $\begin{array}{l}\text { Demineralisation broken enamel-dentine junction but } \\
\text { without obvious spread in the dentine }\end{array}$ \\
\hline $\mathbf{F 3}$ & $\begin{array}{l}\text { Demineralisation with obvious spread in the outer half } \\
\text { of the dentine }\end{array}$ \\
\hline $\mathbf{F 4}$ & $\begin{array}{l}\text { Demineralisation with obvious spread in the inner half } \\
\text { of the dentine }\end{array}$ \\
\hline
\end{tabular}




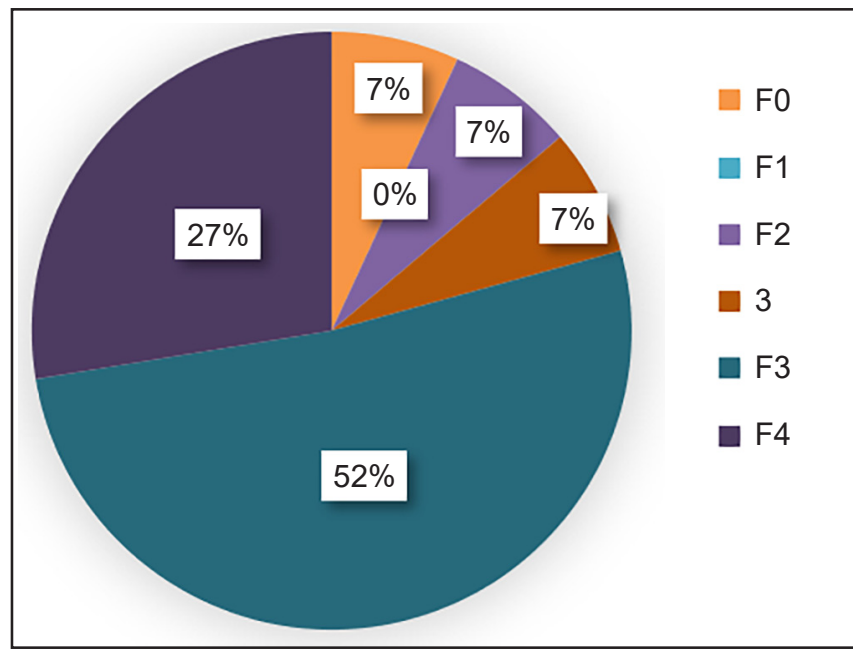

Figure 3. Distribution of digital imaging fiber-optic transillumination (DIFOTI) measured demineralisation scores.

Different colours show the quantity of respective DIFOTI measured demineralisation score.

Table 3. Correlation between the diagnostic findings obtained by digital imaging fiber-optic transillumination and by digital radiography

\begin{tabular}{c|c|c|c|c|c|c}
\hline Scores & F0 & F1 & F2 & 3 & F3 & F4 \\
\hline R0 & 0 & 0 & 0 & 0 & 0 & 2 \\
\hline R1 & 0 & 0 & 0 & 0 & 0 & 0 \\
\hline R2 & 1 & 0 & 0 & 1 & 1 & 1 \\
\hline 3 & 0 & 0 & 0 & 0 & 4 & 0 \\
\hline R3 & 1 & 0 & 2 & 1 & 9 & 3 \\
\hline R4 & 0 & 0 & 0 & 0 & 3 & 2 \\
\hline
\end{tabular}

and agreement between DIFOTI and PA, the Spearman's rank correlation and Kappa were calculated. The Spearman's rank correlation between DIFOTI and PA was $0.031(\mathrm{P}>0.05)$, and kappa was 0.077 , showing poor agreement between the two diagnostic methods.

The DIFOTI and PA scores coincided in $29 \%$ of the cases where demineralisation was obviously spread in the outer half in dentine (respectively, scores F3 and R3), and in $8 \%$ of the cases where demineralisation was obviously spread in the inner half of the dentine (respectively, F4 and R4).

There was a tendency to record greater demineralisation scores using PA, relative to DIFOTI: in $37 \%$ of the cases, the recorded demineralisation depth was higher on PA, and in $26 \%$ of the cases, the recorded demineralisation depth was higher on DIFOTI images.

\section{DISCUSSION}

This study focused on assessing the depth of carious lesions. Accurate caries detection and its outspread

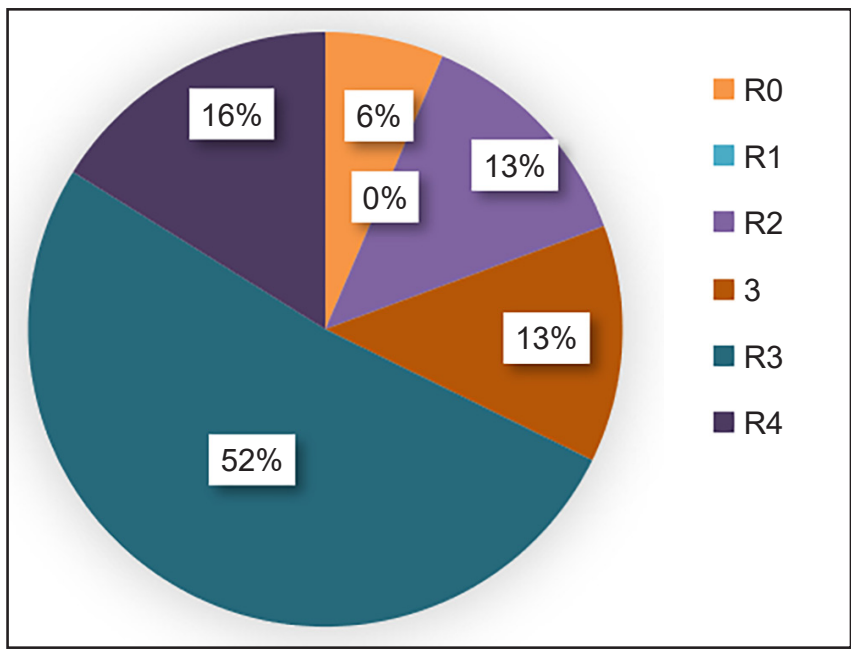

Figure 4. Distribution of radiographically measured demineralisation scores.

Different colours show the quantity of respective radiographically measured demineralisation score.

is important for treatment planning, which is based on the extent of cavitation [2]. In the past, many dentists regarded the restorative approach as the preferred treatment not only for carious lesions extending into dentine, but also for caries lesions only in enamel and without cavitation. However, there are no up-to-date data on the current status of preferred treatment in clinical practise $[\underline{11}, \underline{12}]$. Based on the research, it may be concluded that carious lesions extending more than halfway to the pulp are most likely cavitated [12]. If the lesion extends only into the outer layer of dentine, cavitation may or may not be present. Therefore, to conduct the most minimally invasive treatment, tooth separation should be used to determine the presence of a cavitated carious lesion by gently using a probe (NYVAD) [13]. However, it must be noted that these guidelines for a western population may not be entirely accurate, as most of the studies were conducted approximately 25 years ago; as such, new research is clearly needed to determine the threshold for operative treatment [12].

This in vivo study investigated the depth of dental caries lesion demineralisation as separately determined by DIFOTI and PA. Our findings demonstrate that using DIFOTI and PA to evaluate of the depth of approximal caries lesions does not produce matching results between methods. The same results were reported by Young and Featherstone [3]. The conclusions are also in partial agreement with Lara-Capi et al. []ㅡ, who stated that correlation between DIFOTI and bitewing radiographs in diagnosing approximal carious lesions is low for lesions in enamel. In our research, the PA method was used as the specific method of radiographical examination, instead of bitewing radiographs, 
because it was impossible to make bitewing radiographs. This may be seen as a study limitation, because bitewing radiographs are considered to be golden standard for approximal caries detection [12]. However, the same authors found a complete correlation between the two methods for lesions in dentine; a $95.3 \%$ agreement between the two methods for dentine caries was also found by Sochtig et al. [7]. In our study, dental caries was spread into the dentine in all of the cases, but in $63 \%$ of all cases, demineralisation scores did not coincide.

Although DIFOTI cannot be used as alternative to PA to determine the demineralisation depth of dental caries, DIFOTI may be an advantageous method in terms of the absence of ionizing radiation and reduced patient discomfort it affords [7]. Moreover, images can be viewed in real time and also captured and saved in the database, which makes it easy to monitor dental caries progress; these images are also easily interpreted, even by an inexperienced practitioner $[\underline{5}, \underline{14}, \underline{15}]$. Various recent studies have shown that DIFOTI has a higher sensitivity and is useful for diagnosing early carious lesions as part of the examination and that it can be done prior to radiographic evaluation $[\underline{5,7,15-17]}$. On the other hand, there are contradictory results regarding detection of early caries lesions; the results of earlier studies indicate that DIFOTI should not be the preferred method for detection of lesions within half of the enamel thickness [18].

DIFOTI may be considered as an auxiliary caries detection tool. However, one disadvantage of DIFOTI images is the invisibility of the relationship between the carious lesion and the pulp [7]. This emphasizes the method's deficient accuracy in a case of assessing the depth of carious lesions. Another drawback of DIFOTI is its inability to distinguish carious lesions and development defects. Also, DIFOTI is limited to only the hard tissues of the tooth, which means that it neither identify changes in periodontal structures nor can it see secondary caries lesions underneath the existing restorations [7]. Moreover, it is impossible to use DIFOTI to evaluate the activity of the carious lesion [14].

Considering this, in the present study, DIFOTI and PA yielded the scores of demineralisation expansion that did not coincide and DIFOTI tended to show lower demineralisation scores, relative to PA, DIFOTI may be valuable in routine check-ups, to identify early caries lesions in high-risk caries patients. In contrast, radiographic examination remains more suitable for detection and evaluation of cavitated approximal carious lesions, especially for teeth where this is in doubt $[\underline{5}, \underline{8}]$. However, the most reliable method for diagnosis of approximal caries and treatment planning is a clinical examination [2]. Neither DIFOTI nor radiographic examination can serve as anything other than an auxiliary method for approximal caries diagnosis, because the appropriate type of treatment depends on the presence of cavitation. Aiming to apply the best biologically-oriented treatment and to preserve tooth structure, biological representation of lesions must be established and this object can only be achieved using a visual-tactile method [10].

\section{CONCLUSIONS}

The results of this study show that the demineralisation depths detected by digital imaging fiber-optic transillumination do not coincide with the demineralisation depths detected by periapical radiograph.

\section{ACKNOWLEDGMENTS AND DISCLOSURE STATEMENTS}

The authors reported no conflicts of interest related to this study.

\section{REFERENCES}

1. Rimmer PA, Pitts NB. Temporary elective tooth separation as a diagnostic aid in general dental practice. Br Dent $\mathrm{J}$. 1990 Aug 11-25;169(3-4):87-92. [Medline: 2206652] [doi: 10.1038/sj.bdj.4807281]

2. da Silva Neto JM, dos Santos RL, Sampaio MC, Sampaio FC, Passos IA. Radiographic diagnosis of incipient proximal caries: an ex-vivo study. Braz Dent J. 2008;19(2):97-102. [Medline: 18568221] [doi: 10.1590/S0103-64402008000200002]

3. Young DA, Featherstone JD. Digital imaging fiber-optic trans-illumination, F-speed radiographic film and depth of approximal lesions. J Am Dent Assoc. 2005 Dec;136(12):1682-7. [Medline: 16383050] [doi: 10.14219/jada.archive.2005.0111]

4. Bader JD, Shugars DA, Bonito AJ. A systematic review of the performance of methods for identifying carious lesions. J Public Health Dent. 2002 Fall;62(4):201-13. [Medline: 12474624] [doi: 10.1111/j.1752-7325.2002.tb03446.x]

5. Lara-Capi C, Cagetti MG, Lingström P, Lai G, Cocco F, Simark-Mattsson C, Campus G. Digital transillumination in caries detection versus radiographic and clinical methods: an in-vivo study. Dentomaxillofac Radiol. 2017 Apr;46(4):20160417. [Medline: 28191797] [PMC free article: 5595005] [doi: 10.1259/dmfr.20160417] 
6. Bin-Shuwaish M, Dennison JB, Yaman P, Neiva G. Estimation of clinical axial extension of Class II caries lesions with ultraspeed and digital radiographs: an in-vivo study. Oper Dent. 2008 Nov-Dec;33(6):613-21. [Medline: 19051853] [doi: $10.2341 / 07-167]$

7. Söchtig F, Hickel R, Kühnisch J. Caries detection and diagnostics with near-infrared light transillumination: clinical experiences. Quintessence Int. 2014 Jun;45(6):531-8. [Medline: 24618570] [doi: 10.3290/j.qi.a31533]

8. Ludlow JB, Davies-Ludlow LE, White SC. Patient risk related to common dental radiographic examinations: the impact of 2007 International Commission on Radiological Protection recommendations regarding dose calculation. J Am Dent Assoc. 2008 Sep;139(9):1237-43. [Medline: 18762634] [doi: 10.14219/jada.archive.2008.0339]

9. Lussi A, Hack A, Hug I, Heckenberger H, Megert B, Stich H. Detection of approximal caries with a new laser fluorescence device. Caries Res. 2006;40(2):97-103. [Medline: 16508265] [doi: 10.1159/000091054]

10. Gomez J. Detection and diagnosis of the early caries lesion. BMC Oral Health. 2015; 15(Suppl 1): S3. [Medline: 26392124] [PMC free article: 4580848] [doi: 10.1186/1472-6831-15-S1-S3]

11. Innes NPT, Schwendicke F. Restorative Thresholds for Carious Lesions: Systematic Review and Meta-analysis. J Dent Res. 2017 May;96(5):501-508. [Medline: 28195749] [doi: 10.1177/0022034517693605]

12. Wenzel A. Radiographic display of carious lesions and cavitation in approximal surfaces: Advantages and drawbacks of conventional and advanced modalities. Acta Odontol Scand. 2014 May;72(4):251-64. [Medline: 24512205] [doi: $10.3109 / 00016357.2014 .888757]$

13. Hansen NV, Nyvad B. Non-operative control of cavitated approximal caries lesions in primary molars: a prospective evaluation of cases. J Oral Rehabil. 2017 Jul;44(7):537-544. [Medline: 28301686] [doi: 10.1111/joor.12508]

14. Schneiderman A, Elbaum M, Shultz T, Keem S, Greenebaum M, Driller J. Assessment of dental caries with Digital Imaging Fiber-Optic TransIllumination (DIFOTI): in vitro study. Caries Res. 1997;31(2):103-10. [Medline: 9118181] [doi: $10.1159 / 000262384]$

15. Laitala ML, Piipari L, Sämpi N, Korhonen M, Pesonen P, Joensuu T, Anttonen V. Validity of Digital Imaging of Fiber-Optic Transillumination in Caries Detection on Proximal Tooth Surfaces. Int J Dent. 2017;2017:8289636. [Medline: 29098003] [PMC free article: 5642884] [doi: 10.1155/2017/8289636]

16. Bin-Shuwaish M, Yaman P, Dennison J, Neiva G. The correlation of DIFOTI to clinical and radiographic images in Class II carious lesions. J Am Dent Assoc. 2008 Oct;139(10):1374-81. [Medline: 18832273] [doi: 10.14219/jada.archive.2008.0049]

17. Astvaldsdóttir A, Ahlund K, Holbrook WP, de Verdier B, Tranæus S. Approximal Caries Detection by DIFOTI: In Vitro Comparison of Diagnostic Accuracy/Efficacy with Film and Digital Radiography. Int J Dent. 2012;2012: 326401. [Medline: 23213335] [PMC free article: 3508587] [doi: 10.1155/2012/326401]

18. Ando M. Digital Imaging Fiber Optics Trans-Illumination for Detection of Non-cavitated Lesions. In: Stookey G.K., Kambara M, editors. 83rd General Session International Association for Dental Research Baltimore. Maryland: Symposium Early Detection of Dental Caries. Indianapolis: Moeller Printing Co., Inc.; 2006. p. 41-52.

\section{To cite this article:}

Antipoviene A, Girijotaite M, Bendoraitiene EA.

Assessment of the Depth of Clinically Detected Approximal Caries Lesions Using Digital Imaging Fiber-Optic Transillumination in Comparison to Periapical Radiographs

J Oral Maxillofac Res 2020;11(1):e3

URL: http://www.ejomr.org/JOMR/archives/2020/1/e3/v11n1e3.pdf

doi: $10.5037 /$ jomr.2020.11103

Copyright (C) Antipoviene A, Girijotaite M, Bendoraitiene EA. Published in the JOURNAL OF ORAL \& MAXILLOFACIAL RESEARCH (http://www.ejomr.org), 31 March 2020.

This is an open-access article, first published in the JOURNAL OF ORAL \& MAXILLOFACIAL RESEARCH, distributed under the terms of the Creative Commons Attribution-Noncommercial-No Derivative Works 3.0 Unported License, which permits unrestricted non-commercial use, distribution, and reproduction in any medium, provided the original work and is properly cited. The copyright, license information and link to the original publication on (http://www.ejomr.org) must be included. 